\title{
Ética, natureza e a insistente busca do fundamento último
}

\section{Ethics, Nature and an insistant search for the latest concept}

\author{
José Edmilson de Souza LIMA*
}

\section{RESUMO}

O propósito do presente ensaio é identificar conexões entre alguns autores - filósofos, sociólogos, biólogos e pensadores em geral - que se ocuparam ou se ocupam de temas envolvendo o binômio natureza e ética. Trata-se, portanto, de um estudo exploratório, mas com pretensões de avançar no debate. No primeiro bloco, a idéia é explicitar as possíveis bases para a consolidação do pensamento de Darwin. No segundo bloco, a idéia é tornar visível a rejeição de Weber face à ética da convicção e a qualquer idéia que remeta a fundamentos últimos, acompanhada de sua adesão à ética da responsabilidade. No terceiro bloco, a idéia é identificar pontos de convergências entre a capacidade de "ensimesmar-se" e a criação de uma nova subjetividade humana.

Palavras-chave: natureza, ética, ética da convicção, ética da responsabilidade, subjetividade.

\begin{abstract}
This essay intends to identify connections among some philosophers, sociologists, biologists and savant in general that already studied themes related with ethic and nature. This is an exploratory research, but it intends to advance in the discussion. First of all this essay explains the possible basis of the Darwin's thought. At the second part explains the Weber's refuse about the conviction's ethic and his option for the responsibility's ethic. Finally, this essay identify points of convergency between the capacity of the human being "ensimesmar-se" and the creation of the new human subjectivity. Key-words: nature, ethic, conviction's ethic, responsibility's ethic, subjectivity.
\end{abstract}

\footnotetext{
* Doutorando em Meio Ambiente e Desenvolvimento - Universidade Federal do Paraná; Mestre em Sociologia Política - Universidade Federal de Santa Catarina. Professor das Disciplinas de Humanas da FAE - Business School. <edmilson@bbs2.sul.com.br>
} 


\section{Questões de partida}

A inquietação que motivou o presente ensaio foi tentar explicar por que parece insuportável para muitas pessoas conviver com a incerteza. De um lado, preocupei-me em explicar por que a incerteza gera tanta angústia, tanto sofrimento? De outro, por que a certeza serve de consolo sem necessariamente resolver as grandes tensões e dilemas humanos?

Respostas para as questões acima parecem ser fundamentais para aprofundar o debate em torno dos fundamentos últimos que servem de base para muitos teóricos e estudiosos ocupados com temas ambientais.

\section{Hegel e as bases fundadoras do darwinismo}

Tudo se inicia com Nietzsche. Na "Gaia Ciência", aforismo 357, ele faz uma afirmação muito interessante envolvendo Hegel e Darwin. Para Nietzsche, Hegel remanejou todos os hábitos e comodidades lógicas predominantes em sua época

\footnotetext{
...ao ousar ensinar que os conceitos de espécie se desenvolvem um do outro - proposição pela qual os espíritos na Europa foram pré-formados para o último grande movimento científico, o darwinismo - pois sem Hegel não há Darwin. (NIETZSCHe, 1983, p. 218)
}

O trecho destaca que a citada inovação hegeliana foi pioneira na introdução do conceito de "desenvolvimento" que servirá de suporte para a tese de Darwin acerca da "variabilidade ou mutabilidade dos sistemas vivos". Em outros termos, Hegel prepara o mundo europeu para as suspeitas desconfortáveis e bombásticas de Darwin de que o indivíduo humano não está em patamares tão distantes das outras espécies. Se cada sistema vivo contemporâneo derivou ou desenvolveu-se a partir de sistemas ancestrais, por que razão o "desenvolvimento" da espécie humana seria diferente? A noção de "desenvolvimento", se não desmonta, ao menos põe em dúvida um dos padrões dominantes de pensamento, a crença no "sopro divino" e criador de todas as espécies de forma estática. É a gênese da noção de que a natureza está em permanente movimento.

A crença afirmativa e inabalável no "vir-a-ser" ou na dialética de Hegel, guardadas as devidas proporções, equi-

vale à crença de Darwin (s/d) na idéia de que “(...) todas as formas de vida tendem (...) ao aperfeiçoamento", uma vez que está implícito na formulação de Hegel que o "vir-aser" seguinte é sempre "melhor" que o anterior. Cumpre destacar que quando Darwin faz referência ao "aperfeiçoamento" permanente das espécies, está pensando em termos funcionais, pois sua reflexão está apoiada na dimensão empírica, no mundo prático que envolve todos os organismos vivos. Hegel, por sua vez, ao aceitar a idéia de que o "vir-a-ser" é sempre "melhor", além da dimensão prática da vida associativa, também está remetendo à metafísica, ao mundo das idéias. Em termos epistemológicos, Darwin apropria-se da metáfora idealista de Hegel, aperfeiçoandoa a partir de bases empíricas das ciências naturais, para construir seu próprio padrão de pensamento.

O que Hegel formulou no campo das idéias, Darwin traz para o domínio das ciências naturais. Neste trajeto, Darwin não deixa de fazer justiça a seus predecessores no domínio das ciências naturais. Um dos mais importantes é Lamarck, que viveu antes de dele e produziu sua obra entre final do século XVIII e início do século XIX. De acordo com Darwin, Lamarck

\begin{abstract}
...defende nas suas obras a doutrina de que todas as espécies, compreendendo o próprio homem, originam-se de outras espécies. Foi ele o primeiro a prestar à ciência o grande serviço de declarar que toda alteração no mundo orgânico, bem como no mundo inorgânico, é o resultado de uma lei, e não de uma intervenção miraculosa. (DARWIN, 1987, p. 7)
\end{abstract}

De acordo com a revisão bibliográfica feita pelo próprio Darwin, seu mérito foi apenas explicitar, por meio de evidências empíricas, uma lei da natureza - a da "seleção natural" - que já havia sido suposta em vários autores que o precederam. Dentre os quais, está Lamarck e um elenco de pesquisadores menos conhecidos. Cumpre ressaltar, ainda, que todas as referências de Darwin estão no campo da Biologia.

Vejamos, por exemplo, os comentários de Darwin a propósito das descobertas de Spencer em 1852, sete anos antes de publicar sua obra principal. Para ele, Spencer

(...) estabeleceu com um talento e com uma habilidade extraordinários, a comparação entre a teoria da criação e o desenvolvimento dos seres orgânicos. Extrai os argumentos da semelhança das produções domésticas, das 
transformações que sofrem os embriões de muitas espécies, da dificuldade de distinguir espécies e variedades, e o princípio de gradação geral; conclui que as espécies sofreram modificações que atribui à mudança de condições. O autor (1855) estudou também a psicologia partindo do princípio da aquisição gradual de cada aptidão e de cada faculdade mental (DARWIN, 1987, p. 12).

Quando Spencer fala que as espécies se modificaram graças às mudanças de condições está admitindo a presença forte do "meio ambiente", isto é, da "seleção natural". Está admitindo que as condições externas não podem ser negligenciadas, pois são decisivas para entender as espécies em sua dinâmica. Nas entrelinhas da interpretação de Darwin está o reconhecimento de que Spencer, tal como os outros autores, também já havia percebido os indicadores da seleção natural, só não a explicitou.

Portanto, não é muito correto afirmar que Spencer apropriou-se das formulações de Darwin. Houve influências mútuas, pois, como percebeu Nietzsche, ambos são pensadores alertados pelas metáforas dialéticas de Hegel e pelo vigoroso avanço das ciências naturais ao longo do século XIX. Ocorre que, ao explicitar a "lei da seleção natural”, Darwin ofereceu a Spencer mais subsídios para fundamentar sua teoria social diretamente associada ao "darwinismo social". No momento em que Spencer recorre à "seleção natural" para explicar o mundo social, força a migração de conceitos das ciências naturais para as ciências humanas, transformando sua teoria em possibilidade objetiva não mais de explicação, mas de legitimação da sociedade orientada pelo "salve-se quem puder". Ao tentar explicar o social a partir dos fundamentos últimos da natureza, Spencer, talvez sem se dar conta, demonstra não ter resistido aos encantos da naturalistic fallacy, denunciada por Hume em 1740 (1999). Neste particular, o "darwinismo social" esboçado por Spencer pode ser entendido mais como ideologia legitimadora da filosofia utilitarista vigente na Europa e em especial na Inglaterra (BENTHAM; MILL), do que como teoria social. De qualquer modo, se alguém tiver que tomar a "cicuta", este alguém não deve ser Darwin, mas Spencer, pois Darwin, embora influenciado por Hegel, Bentham, Malthus, Mill e outros filósofos e economistas, construiu sua teoria no domínio das ciências naturais. Foi cauteloso, não se preocupou em dar "saltos" para o mundo das idéias.

Marx (1977), por sua vez, também não escapa - e ele nunca negou isto - do poder de sedução provocado pelo "vir-a-ser" hegeliano. A despeito da vigorosa e inegável originalidade de seu arcabouço teórico, paga tributos a Hegel ao afirmar que a formação social capitalista superou a formação social feudal. A rigor, ele está admitindo, tal como Darwin e Spencer, que uma época histórica presente engendra sua própria superação, preservando sempre seus elementos fundamentais. Nestes termos, o capitalismo surge do feudalismo e, ato contínuo, será superado pela sociedade sem classes, a sociedade comunista. Há de se notar que Darwin faz afirmações em relação à transformação aperfeiçoamento em termos funcionais - das espécies, tomando como referência a mesma lógica ou estrutura de pensamento. A dialética inaugurada por Hegel, portanto, permite e legitima a noção de que uma espécie contemporânea - qualquer sistema vivo ou um sistema social - pode ter surgido de outra completamente diferente e engendrar outra, também, absolutamente diversa.

Ao que parece, a diferença fundamental é que se Darwin entende o sistema vivo como simples resultado das circunstâncias ou "meio ambiente", Marx (1977), ao contrário, leva em conta as circunstâncias como determinações objetivas, mas assevera que o ser humano (sistema vivo) altera constantemente as circunstâncias, mesmo sem ter consciência plena disto. Da mesma forma que Nietzsche, Marx admite, sobretudo para o indivíduo humano, uma "ética" - no sentido que Nietzsche utiliza, isto é, como comportamento ou uso - da transgressão. A despeito das imposições das circunstâncias, Marx e Nietzsche não aceitam a ênfase nos mecanismos de adaptação de Darwin. O sistema vivo humano não apenas se adapta, mas altera-se internamente ao mesmo tempo em que modifica as circunstâncias; trata-se, portanto, das reações não necessariamente de confronto ou de luta pela sobrevivência de um "corpo que pensa" (HEEMANN, 2001) diante de movimentos externos, mas de interação vivencial. Ao falar em um "corpo que pensa", que sente, que se transforma e, principalmente, também transforma o ambiente, parece que Heemann, (diferentemente de Darwin, Descartes (1999) e outros adeptos do dualismo) rejeita a separação dualista entre corpo/ mente e ambiente, admitindo reelaborações. Na mesma perspectiva monista de Heemann, Bateson não hesita em acentuar que, “...en realidad, la unidad de supervivencia es el organismo en un ambiente y no el organismo contra el ambiente" (BATESON, 1993, p. 231). Ao deslocar o eixo da sobrevivência do organismo da luta contra para a relação permanente de troca com o ambiente, Bateson está admitindo a mesma tese de Heemann de que o corpo capaz de pen- 
sar e sentir o ambiente não se define ou se constitui unilateralmente pela luta com o ambiente, pois a distinção entre corpo e ambiente torna-se fluida ou até impossível de ser delimitada.

No fundo, Darwin, com sua crença dualista, incorpora a metáfora de Rousseau (1987) de que o homem é naturalmente "bom" - em termos funcionais ao sistema natural - mas as circunstâncias o corrompem, tornando-o "mau". O equivalente em Darwin seria diferente na conclusão: toda espécie é resultado das circunstâncias, sendo que as adaptáveis, as sobreviventes, ao contrário de Rousseau, são as melhores. Para ele, existem leis intrínsecas às circunstâncias - que ele chama de "natureza" - e estas leis, se não houver intervenções ou quaisquer imponderáveis, conduzem ao "bem", ao aperfeiçoamento funcional das espécies. Neste sentido específico, as circunstâncias simbolizam o "bem" e o indivíduo humano, o "mal". As circunstâncias são intrinsecamente "altruístas" e o indivíduo humano, "interesseiro", "superficial" e "arrivista". Em seus próprios termos,

...a natureza, se me permitem personificar com este nome a conservação natural ou a persistência do mais apto, não se ocupa (...) das aparências, a não ser que a aparência tenha (...) utilidade para os seres vivos.

Em outros termos, a natureza “(...) escolhe para vantagem do próprio ser”. Grosso modo, Darwin, em seu afã de caracterizar a "natureza" como um "bem" em si mesma, não hesita em recorrer às formulações utilitaristas vigentes na época. Nesta empreitada, tende a transferir sua crença afirmativa no utilitarismo para os fenômenos naturais, conferindo-lhes vida e vontade próprias. O homem, por sua vez, aparece como grande imponderável, como ameaça suprema para os outros sistemas vivos porque "...tem apenas um objetivo: escolher para sua própria” (DARWIN, 1987, p. 70).

Ao se aceitar como verdadeiros os pressupostos de Darwin, admite-se que se não houvesse a intervenção humana, não haveria crises no ambiente natural. Significa admitir que as possíveis e profundas causas das "crises ambientais" têm como responsáveis as ações abusivas dos indivíduos humanos. Os vetores desencadeadores das crises ambientais devem ser buscados no sistema sociedade com suas infindáveis contradições. É o sistema sociedade, não o sistema natureza, que "...não permite que os machos mais vigorosos lutem pela posse das fêmeas. Não destrói os indi- víduos inferiores; protege, pelo contrário, cada um deles" (DARWIN, 1987, p. 71).

Este princípio aparece em muitas abordagens preservacionistas que se limitam a defender a natureza não necessariamente por ela conter valores intrínsecos, mas pela desqualificação de um sistema sociedade estribado na predação.

\section{Weber e a rejeição do fundamento último}

Em “A política como vocação", Weber (1968) rejeita a ética da convicção como possibilidade de orientação das decisões humanas mais importantes. Em seus próprios termos,

\begin{abstract}
...toda a atividade orientada segundo a ética pode ser subordinada a duas máximas inteiramente diversas e irredutivelmente opostas. Pode orientar-se segundo a ética da responsabilidade ou segundo a ética da convicção. Isso não quer dizer que a ética da convicção equivalha à ausência de responsabilidade e a ética da responsabilidade, à ausência de convicção. Não se trata disso, evidentemente. Não obstante, há oposição profunda entre a atitude de quem se conforma às máximas da ética da convicção - diríamos em linguagem religiosa, "O cristão cumpre seu dever e, quanto aos resultados da ação, confia em Deus" - e a atitude de quem se orienta pela ética da responsabilidade, que diz: "Devemos responder pelas previsíveis conseqüências de nossos atos". (WEBER, 1968, p. 114)
\end{abstract}

O trecho evidencia que Weber rejeita a ética da convicção porque enxerga na mesma uma insistente e abusiva tentativa de recorrer a um fundamento último, a um poder metafísico, enfim, a um poder divino. Em última análise, Deus seria a base estrutural para todo indivíduo que toma como referência a ética da convicção para decidir o próprio destino. A partir da crença no fundamento último, não há necessidade de legitimá-la em termos terrenos. Nestes termos, Weber não aceita a rigidez, a incondicionalidade da ética da convicção; não aceita sua pretensão de servir de "imperativo categórico" para toda a humanidade. Para ele, o problema da ética da convicção é não estar necessariamente associada a valores íntimos do indivíduo; agir sob a égide de tal ética implica agir, em geral, contra a própria consciência. Na formulação de Weber, isto parece ser inaceitável principalmente no que diz respeito aos líderes, res- 
ponsáveis pelo destino não apenas de si mesmos, mas de toda uma nação.

Agindo sob a ética da convicção, os espaços para a "transgressão" - a mesma transgressão reivindicada por Nietzsche e Heemann - ou para a ação fiel à consciência, ficam reduzidos, pois todo ato simboliza a obediência cega a Deus, à lei ou à norma. Sob tal domínio, a obediência está associada a algo que é externo, que comanda os atos e decisões como se fossem ordens irrefutáveis. Os valores íntimos dos indivíduos são sacrificados em nome do fundamento último. É oportuno lembrar que, ao falar da ética da convicção, Weber está fazendo referências críticas aos burocratas que sacrificam valores íntimos em favor da norma e, pior ainda, em prejuízo da sociedade. A ética da convicção, no sentido que Weber critica, ao desobrigar a consciência, tende a retirar do indivíduo toda e qualquer culpa sobre seus atos.

No domínio da ética da responsabilidade, não há legitimação externa ao indivíduo, pois ele passa a ser o principal responsável por seus próprios atos e decisões. Não existe justificativa metafísica. No raciocínio de Weber, orientado por tal ética o ser humano tende a ser mais cauteloso antes de tomar qualquer decisão, possibilitando relações mais claras e emancipatórias entre as pessoas. Na ética da responsabilidade não há culpados externos ao homem, muito menos imperativos categóricos. Não há projeto intrínseco nem a priori nem a posteriori na decisão humana. O homem está entregue à própria sorte, logo, obrigado a ser cauteloso, a analisar circunstâncias antes de bater o martelo. Na ética da responsabilidade não existe finalismo porque só o homem é capaz de conferir sentido às suas ações. Em outras palavras, Weber está explicitando sua epistemologia, cujo pressuposto é que não existe sentido ou projeto intrínseco aos fenômenos externos à mente humana. A partir desta percepção, Weber entrega ao ser humano o direito de definir seu próprio destino e assumir, sem remorsos, as consequiências advindas das decisões. Não é por acaso que alguns intérpretes do pensamento de Weber - Giddens (1991), é um exemplo - tendem a caracterizá-lo como pessimista e sombrio face ao futuro de uma humanidade conduzida por burocratas servis às normas e por políticos oportunistas que não hesitam em sacrificar valores íntimos em prol de interesses privados. Ao caracterizar Weber como pessimista Giddens está correto, pois Weber não aceitava com tranqüilidade o fato dos governantes alemães terem rompido com facilidade seus limites éticos, suas consciências em nome de prestígio.
Para Weber, os postos-chave de qualquer governo que tenha pretensões de ser politicamente forte, devem ser ocupados não por burocratas, mas por

...políticos - homens experimentados em pesar os efeitos de declinações públicas, homens com o senso de responsabilidade do político e não com o sentido de dever e de subordinação do burocrata, que é adequado em seu lugar, mas pernicioso em política. (WEBER, 1980, p. 61)

O trecho recortado deixa claro que o autêntico político, entre sacrificar o cargo e seus valores íntimos, ele opta pela primeira alternativa; não negocia sua consciência. Com isto, Weber aprofunda a distância que separa o burocrata do político:

...o funcionário público deve sacrificar suas convicções às exigências da obediência; o político deve rejeitar publicamente a responsabilidade por ações políticas que se chocam com suas convicções e deve sacrificar seu cargo a essas convicções. (WEBER, 1980, p. 61)

Ao que parece, o burocrata orienta suas ações a partir da ética da convicção porque apenas obedece a algum imperativo que lhe é externo e pré-estabelecido em forma de regra. Ao agir desta forma, sacrifica seus valores íntimos porque estes podem ou não estar relacionados à crença ou na positividade das regras. O político, ao contrário, em hipótese alguma sacrifica sua consciência porque esta está relacionada à sua crença em convicções íntimas e contrárias à suposta positividade das regras.

Sendo assim, Weber admite a existência de espaço para a substantividade humana a partir do momento que admite que o político, entre o cargo e suas convicções, deve optar pelas últimas. Junto a esta afirmação, Weber está admitindo a possibilidade objetiva de ruptura, de não adaptação do homem à camisa-de-força da burocracia. O burocrata sacrifica sua intimidade mais profunda, submetendo-se à regra; neste movimento de submissão da substantividade humana à norma, além de perpetuar e legitimar a dominação burocrática, permite o massacre, o seqüestro de sua consciência. Eis a gênese do temor de Weber, de sua análise pautada em cenários nebulosos. O político, ao contrário, afirma suas convicções negando veementemente as regras, pondo em dúvida a legitimidade da dominação burocrática. Ao desprezar a norma em prol de sua intimidade, o político garante espaços para a própria auto-realização. 
O conhecido pessimismo de Weber está associado ao fracasso parlamentar alemão e Weber atribui o fracasso ao predomínio da mentalidade burocrática. Sua hipótese é que quanto maior o avanço da burocracia, maior a decadência do parlamentarismo alemão. O desdobramento deste processo é que há uma inexorável negação de espaços para a substantividade humana. Diante de tal cenário, Weber enxerga a política como uma das possibilidades objetivas de garantia ou criação de espaços para a substantividade humana.

Neste particular, a ética preferida de Weber - a da responsabilidade - está mais próxima da ética da transformação de Nietzsche e Heemann, do que da ênfase nos mecanismos de adaptação funcional dos organismos vivos ao ambiente, de Darwin.

\section{Ortega y Gasset e o "ensimesmar-se"}

A associação com as abordagens de Heemann (1998; 2001 e 2002) pode ser construída a partir da ética da responsabilidade. Por meio dela, o corpo pensante também não busca nem procura culpados por erros derivados de suas decisões. Por intermédio da ética da responsabilidade, o corpo pensante consegue realizar aquilo que Ortega y Gasset (1991) chama de "ensimesmar-se"; a capacidade singular do indivíduo humano de voltar-se para si mesmo e compreender sua própria especificidade sem influências ou determinismos sobrenaturais. É a capacidade que o ser humano tem de desvincular-se das imposições externas, das circunstâncias. O "ensimesmar-se" é o instante da sublimação, da criatividade, da percepção clara de que "eu" sou diferente do "outro", mas que me constituo como "eu" a partir das minhas relações com ele. Em suma, é o momento em que palavras podem transformar-se em corpo; é o momento da ética não como figura retórica ou alegoria, mas como vivência.

Ortega y Gasset parte do pressuposto que o ser humano não coincide nem se reduz às circunstâncias; pois consegue desligar-se das pressões exteriores do ambiente. Só o ser humano é capaz de libertar-se das necessidades primárias e ocupar-se de si mesmo; e dedicar-se à arte, à literatura e à poesia. Sempre que esta singular capacidade humana é negada, condena-se o ser humano à marginalidade, pois sua substantividade está sendo seqüestrada. Sempre que o ser humano sentir-se obrigado a viver correndo atrás de prestígio, dinheiro ou comida, as possibilidades dele ensimesmar-se estão sendo negadas. Além do que, pode ser que ele esteja quase transformando-se em máquina.
Assim, o "marginalizado" é aquele que é induzido pelo sistema sociedade, compulsoriamente, a esquecer de si mesmo, a viver tal como vive qualquer lagarto, isto é, sob controle do cérebro reptiliano, preso às necessidades vitais. Seu tempo livre não se transforma, como quer De Masi (2000), em “ócio criativo" ou "emancipador", mas em "ócio destrutivo" e "ameaçador": Sob controle do cérebro reptiliano, o corpo pensante pode embriagar-se não por prazer, mas para tentar fugir de uma situação insuportável, da incerteza. Há quem afirme que o processo civilizatório da humanidade teve e tem como principal combustível a fuga à incerteza. "Sem Deus - profetizava Dostoiévski (1995) - não haveria civilização, uma vez que tudo seria permitido". A existência humana seria menos tolerável se não fosse possível a fuga à incerteza. Daí a necessidade, para muitos, da existência de fundamentos últimos. Cumpre destacar que a fuga à incerteza possibilita tanto a crença em um confortável e externo ente metafísico, como em outro ente, desta vez, interior e solitário: o próprio corpo pensante. Se a busca de um ente metafísico aponta para um estado de resignação face às circunstâncias, o encontro consigo mesmo sinaliza para a transformação ou transgressão das normas impostas pelas circunstâncias.

Nesse sentido, o que importa mesmo guardar da reflexão de Ortega y Gasset é que o ser humano, a despeito das pressões, não coincide com as circunstâncias. Tal afirmação traz embutida outra: a de que não existe fundamento último; o corpo pensante é dono do seu próprio projeto de existência. Ao alterar as circunstâncias para atender necessidades diversas, o corpo pensante inicia o processo de hominização. Em sua leitura afirmativa da "cultura" - que Ortega y Gasset chama de "técnica" - o autor a caracteriza como a capacidade que o ser humano tem de transformar dificuldades impostas pelas circunstâncias em oportunidades concretas de sobrevivência ou simplesmente em conforto. Por meio dela, o ser humano ajusta o ambiente aos seus interesses. A cultura, portanto, sinaliza o distanciamento do ser humano das supostas determinações biológicas. Em seus próprios termos, "um homem sem [cultura], sem reação contra o meio, não é um homem” (ORTEGA Y GASSET, 1991, p. 14). A negação da cultura significa a negação do momento mágico, do instante em que o corpo pensante está preparado para a descoberta do fogo, para a construção de um edifício, para o cultivo de um jardim e, finalmente, para a concepção e produção de um automóvel. Portanto, no "ensimesmar-se" mente e corpo integram-se de maneira plena e singular. Como ensinam Heemann e Bateson, é o momento da percepção de que a mente faz parte do corpo. 


\section{Algumas Considerações Finais}

Nietzsche estava certo ao revelar que sem a dialética de Hegel, nem Marx nem Darwin seriam possíveis, pois os espíritos dos homens não estariam relativamente prontos para recebê-los.

Em certa medida, as análises de Weber nos levam a concluir que o homem, a despeito das circunstâncias, continua sendo a medida de todas as coisas. Nas entrelinhas da rejeição da ética da convicção, Weber esconde seu longínqüo desejo de ver um mundo organizado e conduzido por indivíduos que se orientam pela ética da responsabilidade. É por meio desta que Weber vislumbra possibi- lidades objetivas de garantir espaços para a subjetividade humana em seu significado lato.

O "ensimesmar-se" de Ortega y Gasset é o momento mágico da existência humana; é o momento efetivo da criação de uma nova substantividade.

Finalmente, a reflexão conduz a um ponto apresentado por Nietzsche e que ainda continua defensável: o homem está condenado a decidir e valorar. Ele está admitindo - e Weber faz o mesmo - a não existência de fundamentos últimos. A noção de "valores intrínsecos" à natureza torna-se frouxa face aos presentes questionamentos.

Talvez seja esta a mensagem que o ensaio pretenda reforçar.

\section{REFERÊNCIAS}

BATESON, G. Una Unidad Sagrada: passos ulteriores hacia una ecología de la mente. Barcelona: Gedisa Editorial, 1993.

DARWIN, C. A Origem das Espécies. Rio de Janeiro: Ediouro, 1987.

OS PENSADORES. Descartes. São Paulo: Nova Cultural, 1999.

DE MASI, D. O Ócio Criativo. Rio de Janeiro: Sextante, 2000. $328 \mathrm{p}$.

DOSTOIEVSKI, F. Os irmãos Karamazov. São Paulo: Nova Cultural, 1995.

GIDDENS, A. As conseqüências da Modernidade. São Paulo: Ed. UNESP, 1991.

HEEMANN, A. Ética e Natureza. Curitiba, 19 a 30 ago. de 2002. Tese (Doutorado em Meio Ambiente e Desenvolvimento) - Anotações de Aula.

HEEMANN, A. Natureza e Ética. 2. ed. Curitiba: Ed. UFPR, 1998. 224p.
. O Corpo que Pensa: ensaios sobre o nascimento e a legitimação dos valores. Joinville: Ed. UNIVILLE, 2001.

OS PENSADORES. David Hume. São Paulo: Nova Cultural, 1999.

MARX, K. O 18 Brumário de Luís Bonaparte. Rio de Janeiro: Paz \& Terra, 1977. 1977.

O Manifesto Comunista de 1848. São Paulo: Grijalbo,

OS PENSADORES. Friedrich Wilhelm Nietzshe. 3. ed. São Paulo: Abril Cultural, 1983.

ORTEGA y GASSET, J. Meditação Sobre a Técnica. Rio de Janeiro: Instituto Liberal, 1991. 78p.

ROUSSEAU, J. J. Os Pensadores. 4. ed. São Paulo: Nova Cultural, 1987.

WEBER, M. Ciência e Política: duas vocações. São Paulo: Cultrix, 1968.

OS PENSADORES. Weber. 2. ed. São Paulo: Abril Cultural, 1980 . 